\title{
A construção do espectador teatral contemporâneo
}

The construction of the contemporary theatrical spectator

\section{Leonel Martins Carneiro}

Leonel Martins Carneiro

Professor adjunto do curso de Artes Cênicas/Teatro da

Universidade Federal do Acre

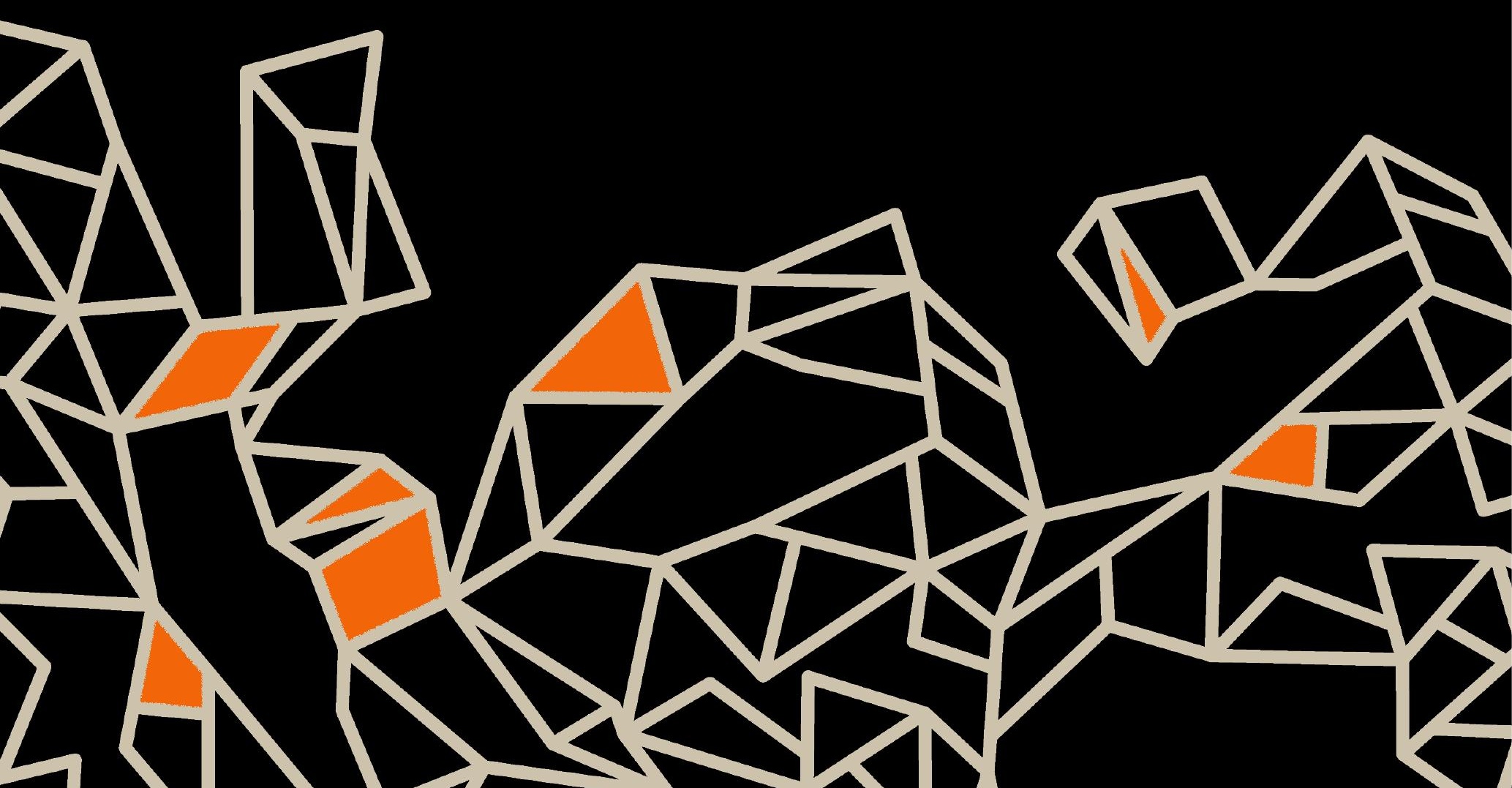




\section{Resumo}

O presente artigo aborda historicamente a construção da figura teórica do espectador teatral contemporâneo. Tal assunto é tratado a partir de uma revisão do lugar do espectador em importantes escritos das áreas de teatro, filosofia, psicologia, antropologia, entre outros, que contribuíram ao longo do último século para a compreensão da experiência do espectador do teatro. Diante de tal quadro teórico, propõe-se a necessidade de aproximar-se a teoria do evento real, produzindo uma reflexão que esteja ancorada em pessoas contemporâneas reais.

Palavras-chave: Contemporâneo, Espectador, Experiência, Teatralidade.

\section{Abstract}

This paper aims to discuss, historically, the theoretical construction of the contemporary theatrical spectator's figure. We approach this subject from a review of the spectator's place in important writings from the fields of theater, philosophy, psychology, anthropology, among others, who contributed in the last century to help us to understand the theater spectator's experience. In face of this theoretical frame, we propose that is necessary to approach the theory of the real event, producing a reflection that is anchored in contemporary real people.

Keywords: Contemporary, Spectator, Experience, Theatricality.

[A arte] é um produto de dois polos: tem o polo daquele que faz uma obra e o polo daquele que a olha. Para mim aquele que olha é tão importante quanto aquele que faz. (Marcel Duchamp, apud CABANNE, 1967)

O estudo do espectador tem despertado o olhar de muitos pesquisadores ao redor do mundo, especialmente a partir do início do século XXI. A questão do espectador deixou, ao longo dos últimos anos, de estar vinculada apenas às teorias estrangeiras do campo teatral, como a da recepção' ${ }^{1}$ Tais teorias têm sido questionadas por apresentarem limitações no que diz respeito a compreensão do lugar do espectador no evento teatral. Diante de tal quadro, o estudo do espectador, considerando-se sua experiência, tem se

1 Teoria que origina dentro do campo dos estudos literários e tem como precursor o trabalho desenvolvido por Hans Robert Jauss nos anos 1960. 
apresentado como alternativa para a construção de uma teoria com base nas práxis sociais que envolvem sua ida ao teatro.

Coloca-se, dessa maneira, a prática do espectador, como uma prática do teatro, comparável à prática atoral e que deve ser desenvolvida ao longo de um tempo em uma cultura que vai influenciá-la. A experiência do espectador do teatro tem como base as experiências anteriores do indivíduo imerso em uma cultura. Esse espectador deve ter uma postura sempre ativa, pois "para perceber, o espectador ou observador tem de criar sua experiência" (DEWEY, 2010, p. 137).

Mas para chegar a esse tratamento teórico da figura do espectador houve um longo caminho de construção que ocorreu concomitantemente ao desenvolvimento da linguagem cênica, passando pela criação da encenação no início do século XX até os movimentos de dissolução do papel do espectador proposto por vertentes do teatro contemporâneo e da performance.

\section{O lugar do espectador}

A figura do espectador é fruto de uma construção que acontece na história e que acaba por influenciá-la. Como nos mostra Mervant-Roux (2006), há uma ruptura histórica entre o espectador das teatralidades contemporâneas e o público que na Grécia Antiga ia aos festivais assistir às tragédias de Sófocles. O teatro grego é diferente daquele que surge na Europa, no final da Idade Média, do qual o teatro atual europeu parece descender. Por outro lado, olhando mais de perto, esse espectador contemporâneo é fruto do processo histórico que começa mesmo antes dos gregos e inclui as rupturas e diferentes desenvolvimentos de sua atividade em diversas partes do globo.

Na Grécia, a importância do espectador mostra-se pela própria etimologia da palavra teatro, que vem do grego théatron (em latim theatrum) que significa literalmente "lugar para olhar" ou o "espaço dos espectadores" (PAVIS, 2012, p. 409). Seria, portanto, o espaço não da ficção ou dos artistas, mas dos espectadores. Por outro lado, algo aconteceu desde a Grécia que modificou a relação do teatro com seu público e, segundo o teórico francês Patrice Pavis (2012, p. 140), este foi "por muito tempo esquecido ou considerado quantitativamente negligenciado". 
O lugar do espectador grego passa por uma mudança de paradigmas ao longo do século XX. Para compreendê-las propõe-se uma análise na alteração que o conceito de lugar, que se referia a um espaço físico na geografia tradicional, passa na segunda metade do século XX. Para um dos mais importantes geógrafos dessa época, o americano Carl Sauer, "A literatura da Geografia, [...] começa com as primeiras sagas e mitos, vividas como o sentido do lugar e da luta do homem com a natureza"2 (SAUER, 1969, p. 317).

A partir do ponto de vista de Sauer (1969) e de outros geógrafos do século XX, o conceito de lugar passa a incorporar a cultura e a subjetividade, sendo reveladas na experiência, como bem resume a definição empreendida por Holzer (1999, p. 71):

Deste modo o lugar se diferencia da cena (scene) ou paisagem, falta a esta a estabilidade, ela se altera a cada mudança de perspectiva; enquanto que o lugar possui uma existência estável (TUAN, 1979), é a experiência, individual ou coletiva, que toma os lugares visíveis. (TUAN, 1975).

O lugar do espectador, está ligado à identidade e à alteridade, e é construído na experiência intersubjetiva do sujeito que presencia o evento teatral, não se limitando ao momento no qual ele ocorre, mas interligando experiências passadas e futuras (expectativas). Portanto, ainda que hajam alterações físicas no lugar, o local propriamente dito do espectador possui uma estabilidade.

\section{A construção do lugar do espectador na teoria teatral do século $X X$}

Ao olhar para as obras escritas por grandes artistas teatrais do século XX, encontram-se diversas vezes preocupações com o espectador. Muitas delas tratam sua figura teatral antes mesmo da obra de Jan Doat (1947), a primeira a se dedicar declarada e especificamente ao assunto. Constantin Stanislávski, por exemplo, faz uma série de proposições em $A$ preparação do ator (2010) que visa, em última instância, um resultado sobre a atenção do espectador (CARNEIRO, 2015).

2 Todas as traduções dos textos em língua estrangeira foram feitas pelo autor e estão identificadas pela sigla N.T. (nossa tradução). 
Todo o trabalho sobre os mecanismos da memória, da atenção e da emoção, desenvolvidos por Stanislávski a partir de conceitos da psicologia, eram pensados como se a cena fosse uma forma de espelho: o que acontece em cena reflete o que acontece na plateia. Assim, seu objetivo final era o de estimular a memória afetiva do espectador dando espaço para as emoções.

Por outro lado, ainda é pouco discutido no Brasil o trabalho de Stanislávski pós-revolução o qual estava inteiramente pautado por abrir o teatro ao povo. O encenador russo primava por uma experiência de seu espectador que considerava as potencialidades do sujeito, não se sujeitando a preconceitos sobre esse público não especializado.

Aconteceu que em 1917 explodiu a Revolução de Fevereiro e em seguida a Revolução de Outubro. O teatro recebeu uma nova missão: devia abrir suas portas às mais amplas camadas de espectadores, àqueles miIhões que até então não tiveram a oportunidade de usufruir os prazeres culturais. (STANISLÁVSKI, 1989, p. 496)

É conhecido que Stanislávski desenvolveu formações práticas desse "novo espectador", focando principalmente em temas como o comportamento esperado para o ambiente teatral. Ao mesmo tempo, com suas peças, ele apresentava ao público as grandes obras do repertório do teatro russo.

De posse dessa informação, não é de se estranhar também que Meyerhold, um de seus discípulos (dissidentes) mais ilustres, invista atenção especial na figura do espectador, realizando pesquisas para sondar a opinião daquele que, para ele, era o "quarto criador".

O método "convencional" pressupõe no teatro um quarto criador, depois do autor, do diretor e o ator: o espectador. O teatro "da convenção" cria uma encenação cujas alusões o espectador deve completar criativamente, com sua própria imaginação. (MEYERHOLD, 2012, p. 176)

Meyerhold chegou a trabalhar com a aplicação sistemática de questionários aos seus espectadores, que eram utilizados para modificações posteriores em suas encenações. Ao colocar o espectador como cocriador do espetáculo, Meyerhold daria origem ao papel que o espectador assume no teatro contemporâneo. Seu teatro era um grande compromisso entre o racional e a sensível: 
O papel das imagens e das situações cênicas é levar o espectador a refletir sobre os mesmos temas que se discutem nas reuniões. Nós estimulamos a atividade cerebral do público. Mas há outro que chama a sensibilidade. Sob a ação do espetáculo, a sala deve passar por um labirinto de emoções. (MEYERHOLD, 2012, p.179)

O teatro de Meyerhold deixava em segundo plano a ilusão naturalista para dar relevo ao papel reflexivo do espectador que não deveria se esquecer nem por um momento que estava no teatro (MEYERHOLD, 2012, p. 89). Dessa maneira, ele antecipava o Verfremdungseffekt (efeito de distanciamento) defendido por Brecht décadas mais tarde. Para alcançar tal comunicação com seu espectador, Meyerhold põe em evidência a materialidade dos corpos e objetos em cena. Toda a mudança de paradigmas proposta por seu teatro colocava, portanto, o espectador no centro.

O movimento do teatro russo aqui representado pelas figuras de Stanislávski e Meyerhold não era isolado. Ele representava a ponta de uma massa de mudanças trazidas pelo início do século XX. É notório que entre as últimas décadas do século XIX e as primeiras do século XX houve uma grande virada da percepção humana.

Entre Rússia e França, destaca-se a figura do público que é tratada pelo inventor da palavra teatralidade, Nicolas Evréinoff, em Le théâtre dans la vie (1930). Ator, autor e encenador russo que vivia na França, Evréinoff ocupou-se da questão do público do teatro, em especial, no capítulo no qual propõe que o "amor pelo teatro" manifesto pelo público seria produto de um instinto teatral, inerente ao ser humano.

Em sua obra, o autor russo abordou o instinto de teatralização e de transfiguração do ser humano, o que de certa maneira fundamentaria o "amor pelo teatro do público". As respostas que o público dá ao ser questionado sobre os motivos de frequentar o teatro podem ser diversas, mas para ele o que leva esse espectador ao teatro é a sua pulsão pela transfiguração, um desejo que estaria ancorado numa teatralidade pré-estética. Por outro lado, permeia também sua obra a noção de que a própria vida seria um teatro e os seres humanos os atores em seus papéis (sociais).

As ideias de Evréinoff não estavam isoladas na França dos anos de 1930. Antonin Artaud também proporia dentre as suas questões uma busca 
pela "vida do teatro, ou seja, o momento originário em que os movimentos da vida enquanto tais são teatro" (ARANTES, 1988, p. 91).

Em 1933, Antonin Artaud lançou Le théâtre de la Cruauté (O teatro da crueldade) que foi seguido pelo lançamento, em 1938, de Le théâtre et son double (O teatro e seu duplo), nos quais abordou o lugar do espectador em seu teatro, dizendo que "no 'teatro da crueldade' o espectador fica no meio, enquanto o espetáculo o envolve" (ARTAUD, 1993, p. 78). Havia um incômodo de Artaud com o teatro que "transforma o público em voyeur" (ARTAUD, 1993, p. 81), incômodo que gerava seu desejo de que o espectador fosse envolvido completamente pelo espetáculo, ou seja, que não houvesse um distanciamento possível.

É para apanhar a sensibilidade do espectador por todos os lados que preconizamos que, em vez de fazer da cena e da sala dois mundos fechados, sem comunicação possível, difunda seus lampejos visuais e sonoros sobre toda a massa de espectadores. (ARTAUD, 1993, p. 83)

O teatro imaginado por Artaud colocava o espectador como ser sensível, central para o teatro, que deveria ser tocado por meio de composições visuais e sonoras. De certa maneira, essa proposta teórica prenuncia o aparecimento da figura do "espectador participante", uma "personagem" do teatro que irá se desenvolver e contaminar os happenings dos anos de 1970 e que atinge propostas radicais como as materializadas pelos experimentos do fim da carreira de Jerzy Grotowski e Allan Kaprow. Tais exemplos mostram que quando a figura do espectador desaparece, o teatro também passa a ser uma espécie de ritual, distanciando-se do jogo.

Tanto para Artaud (1984, p. 88) quanto para Evréinoff (1930, p. 127-128), a questão da atenção do espectador era fundamental. Na vida e no teatro, o espectador às vezes precisa sair do lugar comum, dos "lugares onde sua atenção está a tal ponto adaptada às coisas que lhe preocupam, que não se pode mais adotar uma postura contemplativa" (EVRÉINOFF, 1930, p. 128 N.T.). Se o mundo era um teatro, somos todos, ao mesmo tempo, espectadores. Essa ampliação dos limites do teatral proposta por Evréinoff e de certa maneira por Artaud será, em 1974, retomada pelo sociólogo Erving Goffman em Os quadros da experiência social (2011). 
A obra de Goffman, um dos mais influentes pensadores do século XX, traz um dos olhares mais agudos sobre o espectador da época do século XX.

A compreensão central é a de que a plateia não tem nem o direito nem a obrigação de participar diretamente na ação dramática que ocorre no palco, embora possa do princípio ao fim expressar apreço de uma maneira que os seres que os atores representam no palco podem tratar como se não estivesse ocorrendo. (GOFFMAN, 2011, p. 165-166)

Goffman demonstra em sua fala o retrato de um tipo de teatro no qual o espectador deveria ficar sentado e participar do espetáculo a partir de seu assento, não possuindo nem o direito, nem a obrigação de intervir na ação dramática. Essa realidade era dominante nos anos 1970, quando o autor lança seu trabalho, no entanto ela já não era a única possibilidade de "ser espectador" na segunda metade do século XX.

As raízes das mudanças do lugar podem ser compreendidas quando se volta os olhos para um marco da teoria sobre os espectadores em arte. Em 1934, o filósofo americano John Dewey lança o livro Arte como experiência, no qual discute como a experiência da arte insere-se no percurso de vida do espectador, que está imerso em uma cultura. A base do livro encontra-se em uma obra anterior, Experience and nature, de 1925.

A influência de Dewey e de sua postura diante do espectador talvez não tenha sido sentida logo após a publicação de sua obra, mas apareceria, anos mais tarde, na fala de artistas como Allan Kaprow, um dos pioneiros no estabelecimento do conceito de performance em grupos da segunda metade do século XX, como o Living Theatre ou mesmo na concepção dos jogos teatrais da americana Viola Spolin.

Vale dizer que em Kaprow a figura do espectador vai se diluindo e dando lugar ao do participante da ação. Dessa forma, o artista, inspirado por Dewey, inaugura uma tendência que se espalharia fortemente pelo teatro a partir do fim dos anos 1960. Em diferentes graus, o espectador torna-se participante da ação teatral.

No mesmo período, o Living Theatre lutava pela dissolução das fronteiras entre atores e público e entre arte e vida, chamando os espectadores para participar de sua ação dramática. No Brasil, com forte ligação com o 
Living Theatre, o Grupo Oficina trazia o espectador para dentro da cena e expandia a cena para a plateia.

A perspectiva deweyana fundamenta a mudança, do ponto de vista sobre a recepção e a atuação teatral que Viola Spolin aborda em seu Improvisação para o teatro (2010). A noção do artista cujo talento é um dom é substituída pela premissa de que "todas as pessoas são capazes de atuar no palco" (SPOLIN, 2010, p. 3). Por outro lado, a experiência do espectador passa a ser o foco do teatro produzido, considerando-se que "experienciar é penetrar no ambiente, é envolver-se total e organicamente com ele. Isto significa envolvimento em todos os níveis: intelectual, físico e intuitivo" (SPOLIN, 2010, p. 3).

Enquanto a teoria de Dewey irradiava para o mundo a partir dos Estados Unidos, Bertolt Brecht, na Alemanha, desenvolvia seu teatro épico, no qual o espectador seria o "verdadeiro protagonista". Não seria por acaso que o médico, dramaturgo e diretor teatral Bertolt Brecht incluiria em seu teatro a estrutura dos quadros, utilizada no cinema, e fundamentaria sobre a atenção do espectador seu efeito de distanciamento (Verfremdungseffekt).

Porém, antes de continuar a analisar Brecht, é necessário abordar uma de suas maiores influências: Erwin Piscator. $O$ reconhecimento por parte de Piscator de que "o teatro se tornara desinteressante" (PISCATOR, 1968, p. 145) e de que o cinema dizia muito mais sobre a sociedade daquele tempo do que 0 teatro, o fez pensar em "um teatro que se incumbisse dos problemas de nossa época, que fosse ao encontro da necessidade do público de ver reproduzida a sua existência" (PISCATOR, 1968, p. 145). Dessa forma, ele foi um dos primeiros a colocar as necessidades do espectador, de fato, em primeiro plano.

Brecht, apesar das discordâncias, inspirou-se nas ideias de Piscator e trabalhou com a premissa de que "tanto os personagens como os elementos cênicos devem apenas despertar a atenção do público, e não chocá-los" (BRECHT, 1967, p. 208). Foi um dos que mais se dedicou a pensar em seu público, e toda sua formulação teórica visava a um aprimoramento da comunicação com seus espectadores. Ele tinha certamente algo a dizer para seu espectador e procurava a melhor forma de fazê-lo. Seu efeito de distanciamento ${ }^{3}$, por exemplo, demonstra como o espectador era parte central de seu pensamento.

3 "A criação do efeito-V é algo diário que acontece milhares de vezes; não é nada mais do que uma maneira muito empregada para fazer com que uma coisa se torne compreensível 
O que mais parecia incomodar o dramaturgo alemão era a aparente passividade do espectador do teatro. Ele queria provocar esse espectador de forma que refletisse sobre o que estava vendo.

Entremos numa dessas casas de espetáculos e observemos o efeito que o teatro exerce sobre os espectadores. Um olhar em volta, vemos figuras imóveis numa condição peculiar: parecem reter os músculos, em forte tensão, quando não estão relaxados por intenso esgotamento. Quase não se comunicam entre si; é como se todos dormissem profundamente, sendo simultaneamente vítimas de pesadelos, por estarem, como diz o povo, deitados de costas. Verdade, seus olhos estão abertos, mas olham mais do que veem, escutam, mais do que ouvem. Olham para o palco como que fascinados, numa expressão que vem desde a Idade Média, os dias das feiticeiras e padres. Ver e ouvir são atos que causam às vezes prazer, mas estas pessoas parecem distantes de qualquer atividade, são antes objetos passivos de algo que está sendo feito. (BRECHT, 1967, p. 193)

O problema principal apontado por Brecht é que o espectador fruía o espetáculo de maneira desatenta, não sendo possível uma posterior reflexão sobre aquilo que tinha visto. Assim, ele começou a pesquisar, na teoria e na prática, formas de despertar a atenção do espectador sempre que este estivesse a ponto de entrar na ilusão da ficção teatral.

Pode-se dizer que se a atenção seria um dos eixos principais de seu teatro épico, o espectador é o sujeito que está no centro deste teatro. Ainda que, como Meyerhold, Brecht se focasse em um tipo de recepção mais racional por parte de seu espectador, ele de maneira nenhuma ignorava a importância das emoções na recepção teatral.

O ponto essencial do teatro épico é, talvez, que ele apela menos para os sentimentos do que para a razão do espectador. Em vez de participar de uma experiência, o espectador deve dominar as coisas. Ao

aos outros ou a si próprio. Ele pode ser observado durante o estudo ou nas conferências de negócios em uma forma ou em outra. $\mathrm{O}$ efeito- $\mathrm{V}$ consiste em transformar a coisa dada que deve ser tornada compreensível, para a qual a atenção deve se dirigir, e que é comum, conhecida, em uma coisa especial, inesperada, que chama a atenção. Aquilo que parece ser óbvio, é transformado de uma certa maneira em algo incompreensível, mas isto só é feito para que ela se torne mais compreensível. Para que algo conhecido seja compreendido é necessário que seja objeto de atenção, precisa ser eliminado o hábito de não procurar uma explicação." (BRECHT, 1967, p. 173-174) 
mesmo tempo, seria completamente errado tentar negar a emoção a esta espécie de teatro. Seria o mesmo que negar emoção à ciência moderna. (BRECHT, 1967, p.41)

Mesmo que não denomine o espectador como cocriador, Brecht procura dar-Ihe o domínio sobre o teatro. Ele pode escolher, posicionar-se diante da peça. Penso que aí está uma das primeiras iniciativas (ao lado da de Meyerhold) de dar um papel de protagonista para o espectador.

Boa parte do século XX foi marcada por um descontentamento de artistas com as práticas espectatoriais instauradas no século anterior. Os primeiros frutos desta insatisfação seriam colhidos na década de 1960, com o advento da revolução cultural, ponto de virada para a prática do espectador. Essa virada, já apontada como desejada e necessária desde o início do século por artistas, se concretizaria de forma radical a partir da teoria e da prática de Augusto Boal, apontado por Richard Schechner, diretor da companhia The Drama Review, como o concretizador do sonho do teatro brechtiano (ALMADA, 2012). A poética proposta por Boal coloca o espectador na posição de atuação.

Para que se compreenda bem esta Poética do Oprimido deve-se ter sempre presente seu principal objetivo: transformar o povo, "espectador", ser passivo do fenômeno teatral, em sujeito, ator, em transformador da ação dramática. (BOAL, 1980, p. 126)

Se o teatro de Brecht visava ao empoderamento do espectador, Boal propõe que este possa ir além, assumindo ele próprio o curso da ação. De fato, o mesmo diretor que inicia seu trabalho no Teatro de Arena com peças que mostram e discutem a realidade social vai aos poucos caminhando para a participação do espectador. Este se torna agente da ação, gerando experiências teatrais limites, nas quais o espectador passa a ser o protagonista do teatro.

Aristóteles propõe uma Poética em que os espectadores delegam poderes ao personagem para que este atue e pense em seu lugar; Brecht propõe uma Poética em que o espectador delega poderes ao personagem para que este atue em seu lugar, mas se reserve o direito de pensar por si mesmo, muitas vezes em oposição ao personagem. Produz-se uma "conscientização". O que a Poética do Oprimido propõe é a própria ação! O espectador não delega poderes ao personagem para que atue 
nem para que pense em seu lugar: ao contrário, ele mesmo assume um papel protagônico, transforma a ação dramática inicialmente proposta, ensaia soluções possíveis, debate projetos modificadores: em resumo, o espectador ensaia, preparando-se para a ação real. Por isso, eu creio que o teatro não é revolucionário em si mesmo, mas certamente pode ser um excelente "ensaio" da revolução. (BOAL, 1980, p. 126)

O provocativo texto de Boal coloca o espectador como agente do teatro, dando origem ao espect-ator ${ }^{4}$, tendência que seria seguida de perto por encenadores mundo afora. Deve-se notar que, ainda que o espectador possa exercer o papel do ator no teatro do oprimido, sempre haverá outros espectadores a observá-lo. Na proposta de Boal não há um desaparecimento do espectador, mas uma espécie de revezamento que pode ser encontrado tanto no teatro francês medieval e como no teatro amador.

Ainda no Brasil da década de 1960 consolida-se o Teatro Oficina, cuja arquitetura possui elementos que eliminam a divisão física entre palco e plateia. As peças dirigidas por Zé Celso ficaram famosas, dentre outros motivos, por instigar a participação dos espectadores na ação cênica. Ainda que estes espectadores não participem da ação cênica, eles estão em cena todo o tempo, tendo em vista que a estrutura do teatro faz com que os espectadores se vejam durante todo o tempo.

No fim da mesma década de 1960, o diretor polonês Jerzy Grotowski publica Em busca de um teatro pobre (1968 em inglês, publicado no Brasil em 1971) no qual declara: "nossas produções são investigações do relacionamento entre o ator e a plateia" (GROTOWSKI, 1971, p. 2). Investindo nesse relacionamento, o diretor considerava que "a essência do teatro é um encontro" (GROTOWSKI, 1971, p.41). Ao longo dos anos, o trabalho de Grotowski desenvolveu-se no sentido de tornar o teatro uma experiência quase ritualística, na qual a figura do espectador fica imersa na realidade teatral.

Poder-se-ia somar à fala de Grotowski a de tantos outros artistas e teóricos da cena que abordaram a questão do espectador, especialmente no campo da performance. No entanto, não adentramos em tais discussões pre-

4 Espect-ator é o nome dado por Boal ao espectador que passa pela experiência de ator no espaço cênico debatendo cenicamente questões relacionadas ao problema de que trata o espetáculo. 
ferindo o campo mais restrito ao teatro, sendo que os estudos até aqui mencionados tratam da questão do espectador. De certa maneira eles subsidiam o campo de estudos dos estudos do espectador, que surge na década de 1940 e desenvolve-se fortemente a partir dos anos 2000.

\section{A criação do campo teórico dos estudos do espectador}

Em meados do século XX surge no campo dos estudos teatrais, pela primeira vez, um conjunto de reflexões sobre o espectador teatral, dando origem a um campo específico de estudo dentro de tal teoria. Ela se inicia de maneira tímida na década de 1940 e ganha força e forma, especialmente nos anos de 1990.

Pode-se dizer que a teoria do espectador moderna tem origem nas reflexões do encenador francês Jan Doat, que escreve em 1947 o livro Entrée du public, no qual ele parte das teorias da psicologia (em especial da psicologia coletiva) para analisar o comportamento e as emoções do público teatral.

Retomando Evréinoff (1930), Doat fala sobre o instinto de teatralidade do ser humano e, após analisar a atividade do espectador, conclui que "o teatro ultrapassa o estético" (DOAT, 1947, p. 62 - N.T.). Para Doat, o teatro só pode surgir como expressão do pensamento de uma sociedade e é feito para essa sociedade (público) que se identifica com o apresentado. Ele nota, porém, que no contexto pós-Segunda Guerra esse público estaria desaparecendo (assim como a noção de comunidade) e dando lugar aos espectadores "que assistem individualmente à representação" (DOAT, 1947, p. 81 - N.T.). Fala também sobre a diferença entre "le public" (o público), uma "multidão organizada, unida pelo mesmo ponto de vista sobre a ação dramática" (DOAT, 1947, p. 82 - N.T.), comunidade social indivisível e "des publiques" (público), aquele que está presente na plateia do teatro, mas que não necessariamente representa uma comunidade. Em Doat, vê-se o retrato de uma transição que também havia sido abordada por Dewey (2010), na qual a experiência individual dentro de uma cultura passa a ser nomeada e ganha forma.

Dez anos após o lançamento do livro de Doat, David Victoroff traria uma grande contribuição com sua obra L'applaudissement, une conduite sociale (1957) que, apesar de curta, apresenta dados muito interessantes. Partindo de alguns dos apontamentos já revelados em seu artigo "Le paradoxe du 
spectateur" (1955), Victoroff mostra como o aplauso é uma conduta social construída, ou seja, que a prática do espectador é fruto de seu contexto social.

O aplauso, que para Darwin podia ser um movimento sem objetivo, expressão de uma forte alegria, é codificado pelo teatro como um sinal de aprovação. Para Victoroff, não são os indivíduos que batem palma, mas o público, pois "nós não aplaudiremos se nos sentirmos isolados" (VICTOROFF, 1957, p. 132). Dessa forma, o aplauso seria sempre um momento de validação coletiva do espetáculo e, se a palma pode ser um reflexo na vida, "o aplaudir no teatro é uma reação altamente social" (VICTOROFF, 1957, p. 167 - N.T.).

A história social do aplauso de Victoroff mostra como a prática do espectador que temos hoje em dia foi construída. Criou-se uma espécie de manual de boas práticas para o espectador, que foi colocada para este por uma "formação" quase sempre escondida. O autor traz informações interessantes, como a de que não há traços do aplauso no teatro da Idade Média francesa ou que, entre os séculos XVII e XVIII, se aplaudia tudo nos espetáculos. Por outro lado, o hábito atual do aplaudir no teatro parece ter se consolidado a partir do século XIX, com a difusão da claque e com regras específicas para o aplauso ${ }^{5}$.

Desse modo, posso dizer que a obra de Victoroff se concentra em uma primeira mudança ocorrida no século XIX, desnaturalizando a formação do público. Ele, assim como Doat anos antes, demonstra que a atividade do público está sempre em mudança que dependem, em grande parte, mas não somente, de projetos dos criadores teatrais.

Na década de 1960 é a vez de Bernard Dort lançar Théâtre public (1967), no qual desenvolveu um agudo olhar sobre a figura do espectador e sua relação com a cena, diferenciando o processo na cena aristotélica da proposta por Beckett.

5 O texto de Victoroff (1957) é realmente muito interessante e traz dados como o de que, em 1820, foi aberta uma agência para a contratação de claqueurs (p. 153). Também nesse estudo apresenta contratos firmados entre o teatro e essas pessoas, e aponta a ligação entre a figura do claqueur e do siffleur, espectadores profissionais que coordenavam os momentos de aplaudir, bem como incitavam o público à aprovação. Uma figura dessas, infiltrada na plateia com seu grupo (cada claque era formada por um grupo de indivíduos), poderia dar a impressão a um desavisado de que todos tinham gostado do espetáculo, ainda que isso não fosse verdade. 
Em um teatro do tipo aristotélico, a cena e a sala são o espelho uma da outra. A cena reflete a sala; a sala reflete a cena. O que se representa sobre o palco é a mesma história daqueles que estão lá, do outro lado na plateia. A ação da obra, sua fábula, traz a mesma verdade de seus espectadores. $\mathrm{E}$ a cena entrega literalmente, à sala, os problemas de sua história. De onde emana a catarse, [...] a cena becketiniana não é nada mais que o inverso da cena clássica. Uma cena onde não se produzirá um encontro decisivo, onde o conflito não terá lugar. Uma cena que se recusa toda a sala. Uma cena desesperadamente privada. [...]. O jogo de espelhos do teatro aristotélico está somente bloqueado, não foi abolido. E se precisa de pouca coisa para que o espectador veja a sua própria imagem, enobrecida, através do espelho. (DORT, 1967, p. 364 e 374 - N.T.)

A ideia trazida por Dort nesse texto é fundamental, mas recebeu ao longo das últimas décadas pouca atenção. O mesmo autor escreve em La vocation politique uma nova reflexão na qual aborda o espectador (1986, p. 233-248). Nesse texto, ele trabalha com a noção de que o público do teatro constitui um grupo, o que o diferenciaria do espectador solitário do cinema. $\mathrm{O}$ teatro é uma experiência que possui sempre uma dimensão coletiva.

O público da sala [de espetáculos] não é constituído apenas de indivíduos reunidos pelo acaso: rapidamente eles se constituem em um grupo, em uma microssociedade (e esta pode ser mesmo por definição; cada teatro, dizemos, tem seu público). Este público não tem nada de uma reunião de indivíduos separados e solitários. Reparem nos espectadores de salas escuras de cinema: cada um está isolado do outro, enfiado em sua poltrona, como se estivesse sobre em uma ilha deserta, cada um vive apenas para si e para tela. No teatro, pelo contrário, é impossível não "sentir" o outro, não adivinhar a sua presença, suas reações individuais e de não ser perturbado ou influenciado por elas. (DORT, 1986, p. 234 - N.T.)

Em 1988, quando Dort publica La représentation émancipée, ele resume, de modo claro e preciso, o papel que o espectador assume diante da emancipação progressiva dos componentes da encenação teatral. Para Dort, o espetáculo questiona, através de seu jogo, sua significação e coloca para a figura do espectador o papel da criação de sentidos para essa teatralidade.

A teatralidade, dessa forma, não mais é somente uma "espessura de signos" da qual falava Barthes. Ela é também o deslocamento dos signos, a 
sua impossibilidade de articulação, sua confrontação sob o olhar do espectador dessa representação emancipada. (DORT, 1988, p. $183-$ N.T. $)^{6}$

Em 1981, Anne Ubersfeld lançou, em Lire le théâtre: l'école du spectateur, uma das mais importantes tentativas de abordagem do espectador teatral através de ferramentas semiológicas. Em seu Lire le théâtre 2: l'école du spectateur, Ubersfeld busca criar as bases para uma leitura semiológica da atividade dos espectadores. Esse livro seria reeditado em 1996 com acréscimos, em especial no que concerne ao espectador.

Em 1982, Anne-Marie Gourdon pesquisadora do CNRS (Centro Nacional de Pesquisa Científica da França) lança o livro Théâtre, public, perception, que me parece uma das primeiras tentativas de abordagem sobre espectadores reais, feita por meio de uma pesquisa de campo no TNP (Teatro Nacional Popular) ${ }^{7}$ e na Comédie-Française, ambos na cidade de Paris (França). Seu estudo propunha uma análise quantitativa de questionários aplicados a mais de 5.800 espectadores. Nesse estudo, aparecem questões interessantes levantadas pelo público e como este queria um teatro no qual pudesse jogar com o ator (GOURDON, 1982, p. 108).

Nota-se que todos os livros que trataram do espectador até os anos de 1980 o fizeram tomando como base a figura sentada em teatros ao redor do mundo e considerando apenas o momento em que ocorria o evento teatral, como momento de produção de significados. Portanto, esses espectadores não eram considerados de maneira integral, em sua experiência real, mas como números e projeções hipotéticas.

Uma das primeiras pesquisas que abordou o espectador como ser integral foi realizada entre 1985 e 1995 pela pesquisadora do CNRS Marie-Madeleine Mervant-Roux e publicada, em 1998, sob o título L'assise du théâtre.

6 A citação de Dort faz referência ao texto de Roland Barthes, da década de 1960, sobre o teatro de Baudelaire que postulava que "A teatralidade é o teatro menos o texto, uma espessura de signos e de sensações que se edifica no palco a partir do argumento escrito, é aquela espécie de percepção ecumênica dos artifícios sensuais, gestos, tons, distâncias, substâncias, luzes, que submerge o texto sob a plenitude de sua linguagem exterior" (BARTHES, 2002, p. 304).

7 É importante dizer que o espectador do TNP já estava acostumado a responder questionários, segundo uma prática implementada por Jean Vilar desde que assumiu a direção do teatro (1951/1952). Penso que Vilar pode ser considerado um dos maiores pesquisadores da prática do espectador. Ele desenvolveu grande parte do teatro que temos acesso hoje, sempre em estrito diálogo com seu público (WEHLE, 1981). 
A grande diferença do estudo de Mervant-Roux em relação aos demais é a análise que toma por base a perspectiva histórica e antropológica, provocando uma fricção constante entre os espectadores reais e suas figurações teóricas. Tal operação é repetida e aprofundada pela pesquisadora em 2006 , com a publicação de Figurations du spectateur, e, anos mais tarde, retomando o tema do espectador em um de seus artigos mais recentes sobre o assunto, Mervant-Roux conclui que:

A função da figura que chamamos de "espectador" é sim fundamental, embora não seja exatamente o que se poderia esperar. Enquanto o momento da apresentação é certamente essencial (parece termos confirmado isto completamente), a relação da plateia com o teatro não pode ser restrita a esse momento. A lição da antropologia histórica é que o teatro na Europa é um dispositivo criado pela sociedade a fim de elaborar ficções que, por sua vez, ajudam a constituir a sociedade. A operação da função dramática, portanto, depende em grande parte daqueles que comparecem à apresentação, vindo de fora e indo embora depois. (MERVANT-ROUX, 2013, p. 21)

Destaco a informação de que a "operação da função dramática" depende, em grande parte, do espectador. Não se deve misturar, entretanto, a função dramática social com a operação do drama, que será amplamente realizada pelo espectador, especialmente na cena contemporânea.

O espetáculo que passa a incluir o espectador em sua trama "ficcional" deixa, muitas vezes, de oferecer uma narrativa dramática pronta. Ao mesmo tempo, essa narrativa não deixa de ser criada pelo espectador como maneira de articular sua memória do espetáculo. Como observou Mervant-Roux (2006, p. 48 - N.T.), "[...] mesmo se um espetáculo não é dramático, mesmo se ele não foi objeto de nenhuma construção dramatúrgica consciente ou inconsciente por parte dos criadores, o espectador o dramatizará".

\section{A consolidação do campo teórico do espectador no século XXI}

O início do século XXI trouxe consigo a consolidação dos estudos do espectador como campo teórico dos estudos teatrais. A partir dos anos 2000, 
uma série de publicações e eventos passam a abordar o tema, fomentados em grande parte pelas alterações no ato do espectador proporcionadas pelas teatralidades contemporâneas.

Ao analisar tais publicações, constata-se que a interdisciplinaridade é uma característica pujante. Seguindo essa observação propõe-se uma divisão que reconhece a origem da corrente de pensamento sobre a qual o estudo edifica-se. As cinco abordagens principais identificadas são: histórica, sociológica, estudos da recepção, filosófica e experiencial. É claro que cada estudo tem sua abordagem e recorte para tratar do tema, mas de maneira geral há um foco que se sobressai em cada um deles.

A primeira e mais volumosa parece ser a que trata o espectador por um viés histórico. Esse tipo de estudo pode traçar um histórico da figura do espectador e de seu hábito, como bem mostram os artigos presentes no livro Le spectateur de théâtre à l'âge classique (2008). Outro livro que tem o mesmo espírito, inclusive como forma de uma coleção de textos de vários autores, é Au théâtre! (2014), organizado por Pascale Goetschel e Jean-Claude Yon, com a diferença de que enquanto o primeiro analisa a prática do espectador entre os séculos XVII e XVIII, o segundo ocupa-se de sua constituição nos séculos XIX, XX e XXI. Ambos os livros optam por uma abordagem da história não como uma linha contínua, mas através de quadros que revelam o desenvolvimento da figura do espectador.

Au théâtre! (2014) tem o trunfo de trazer experiências de saídas ao teatro que extrapolam o contexto europeu, incluindo estudos de caso de Nova York (Estados Unidos) e Rio de Janeiro (Brasil). Também aponta uma continuidade dessa saída que começa antes de o evento teatral e que continua depois que acaba.

Outra possibilidade de abordagem é a que Christian Ruby faz a partir da história do conceito filosófico do espectador entre os séculos XVIII e XX. Em La figure du spectateur (2012), Ruby traz questionamentos sobre o lugar que essa figura ocupa e sua experiência a partir de autores como David Hume, Denis Diderot, Kant, Rousseau, Merleau-Ponty, Baudelaire, entre outros.

Ainda na categoria histórica, tendo como principal vertente a política, Olivier Neveux traz em seu Politiques du spectateur (2013) uma nova visão 
sobre a política que está profundamente enraizada no teatro e no ato do espectador. Entre os campos da sociologia e da filosofia, Gareth White, em Audience Participation in theatre (2013), propõe uma análise da participação do público no teatro.

Entre a sociologia e a história está o livro de Marie-Madeleine Mervant-Roux Figurations du spectateur (2006), que aborda a teoria do espectador a partir de um olhar da antropologia teatral desenvolvida por Elie Konigson. Na mesma linha sociohistórica, segue Le plaisir du spectateur de théâtre (2002) de Florence Naugrette. Helen Freshwater, por sua vez, propõe uma abordagem sociohistórica cobrindo casos europeus e norte-americanos em Theatre \& audience (2009). Também em In vivo (2011) Anne Gonon faz uma análise da figura do espectador nas artes de rua (e ao mesmo tempo da própria formação desta arte no período pós-1968) e coloca em alguns momentos experiências pessoais dessas teatralidades.

Em How theatre means (2014), Ric Knowles parte da história para realizar uma pesquisa sobre a recepção teatral, buscando desvendar os segredos de como o teatro cria seus significados e propondo análises de espetáculos. Também em uma abordagem histórico-cultural dos estudos da recepção, Flávio Desgranges traça em A inversão da olhadela (2012) alterações no ato do espectador teatral. No mesmo campo dos estudos da recepção, com foco na estética, Catherine Bouko lança Théâtre et réception (2010). Em três continentes distintos esses autores refletem sobre a significação do teatro e o papel do espectador no teatro contemporâneo.

Poderia citar ainda no campo dos estudos da recepção a nova edição de L'analyse des spectacles (2012), na qual Patrice Pavis acrescenta dois novos capítulos que tratam do espectador contemporâneo. Outro livro que apresenta estudos multifacetados, mas que poderia ser colocado no campo da recepção, é Place au public (HUNKELER et al, 2008), resultado de um colóquio ocorrido em Zurique sobre o espectador contemporâneo. Colocaria ainda a proposta de Immersive theatres (2013), de Josephine Machon, no âmbito das produções dos estudos da recepção.

Apesar de não abarcar todas as publicações sobre o assunto, esses livros dão uma boa ideia do que tem sido produzido e divulgado nesses últimos anos sobre o espectador. A maior parte deles têm em comum um olhar para 
um espectador teórico e centrado no contexto europeu e norte-americano, seja pelas teorias ou pelos exemplos utilizados.

\section{A expansão do campo teatral e a multiplicação dos lugares do espectador}

Diante do longo percurso histórico apresentado, que cobre boa parte do que foi produzido nos séculos $X X$ e $X X I$, propõe-se uma reflexão sobre algumas ideias acerca do lugar do espectador e da relação entre sua figura teórica e sua prática.

Aparentemente, durante a maior parte do século $X X$ era pressuposto quase inquestionável que o lugar físico do espectador era sentado na poltrona de um edifício teatral. Esse assento era visto por alguns teóricos como um lugar de "passividade", contra o qual era necessário lutar. Para outros, no entanto, ainda que sentado, o espectador agia sobre o espetáculo, modulando-o tal qual um ressonador.

O espectador nesse lugar, pode-se dizer, "clássico," sentado em sua poltrona, está de maneira geral separado fisicamente do ator e pode olhar com certa distância a cena. Pode se identificar com o que the é apresentado, dissolvendo-se na trama ou também ser levado a refletir sobre sua vida. como propunha Brecht.

Acontece algo muito curioso a partir dos anos de 1960, quando ganha vulto a ideia deweyana de que a arte (e o teatro incluso) proporcionaria uma experiência. Alguns artistas passam a pesquisar e desenvolver não mais peças de teatro dramático, mas experiências teatrais, visando que elas sejam de cunho significativo. A teoria que trata do teatro e do espectador parece continuar alheia ao que acontecia nas encenações que cada vez investiam mais na radicalidade, diluindo a linha que separava palco e plateia.

Bob Wilson, Jan Fabre, Romeo Castellucci e tantos outros encenadores (com origem nas artes visuais) passam a investir, a partir dos anos de 1980, em experiências de imersão que transformam o ato do espectador sem alterar, na maior parte dos casos, seu lugar físico. Ele passa a ter que compor mais e mais a peça a partir de sua experiência. As obras tocam todo o corpo do espectador, especialmente a partir do som que é fundamental para esse tipo de teatro. 


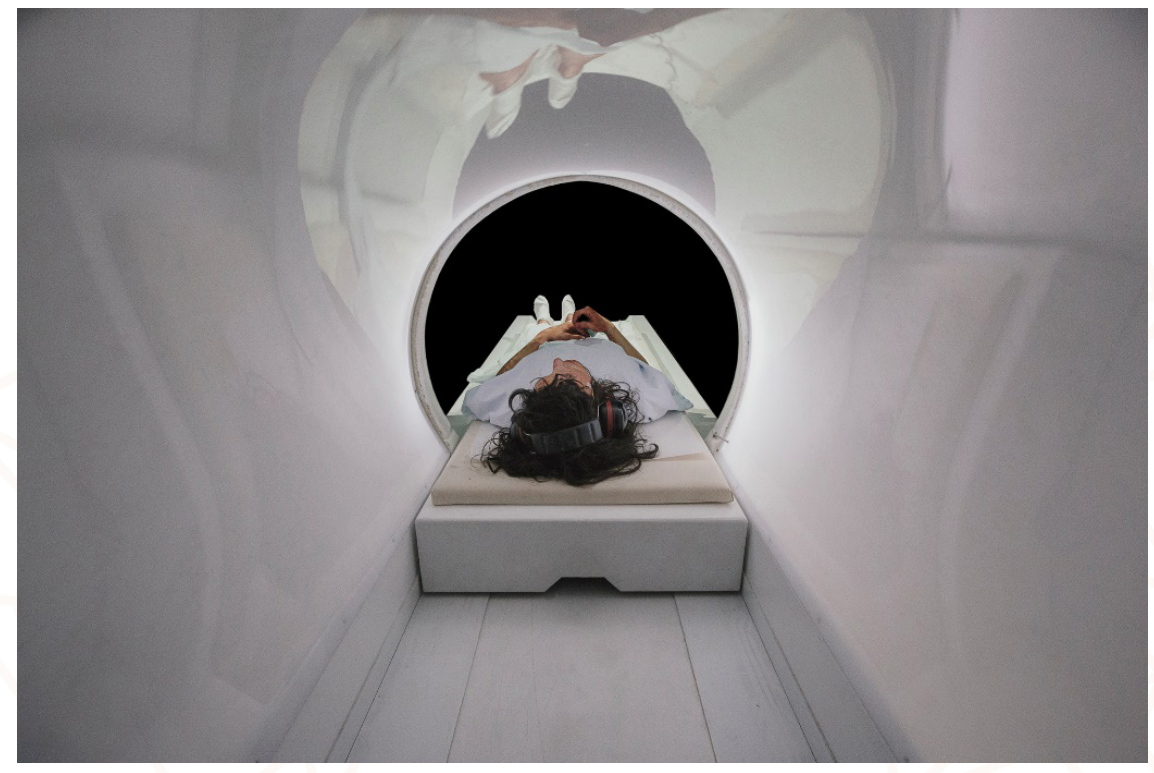

Figura 1 - Espetáculo Go Down, Moses (2014). Direção Romeo Castellucci. Foto: Guido Mencari.

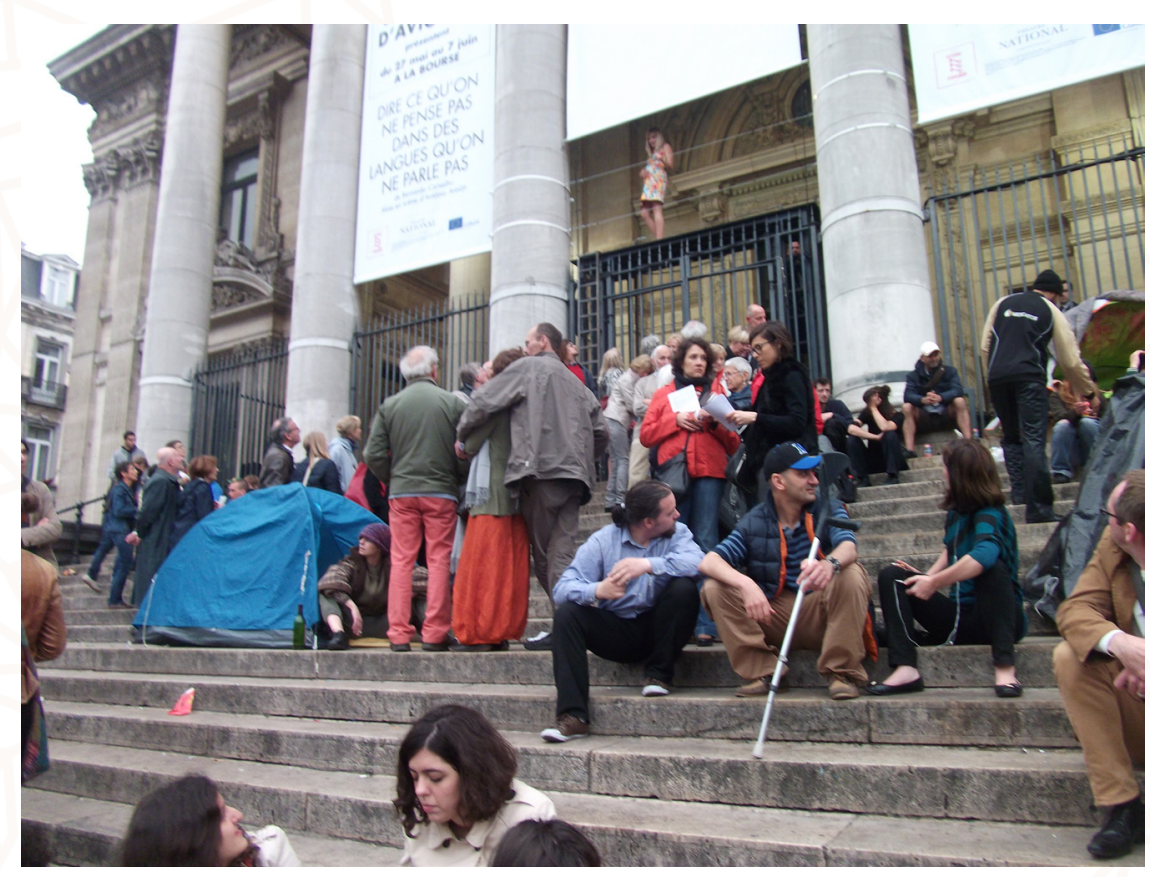

Figura 2 - Espetáculo Dire ce qu'on ne pense pas dans des langues qu'on ne parle pas (2014).

Direção Antônio Araújo. Foto: Leonel Carneiro.

Enquanto alguns artistas optam por levar ao extremo a experiência do espectador, sem retirá-lo do conforto de sua cadeira e utilizando o edifício teatral, outros grupos, como o Teatro da Vertigem, dão preferência a lugares não 
convencionalmente utilizados para apresentações teatrais. O lugar físico e cultural do espectador é alterado e, muitas vezes, o espectador é levado a experiências de imersão quase completa, na qual confunde-se ficção e realidade, ator e espectador. Ao mesmo tempo em que o espectador observa o ator, ele é observado como parte do espetáculo pelo transeunte. Este transeunte, por sua vez, é observado por atores e espectadores como parte do espetáculo-cidade.

Há casos nos qualis os próprios espectadores são convidados a estar em cena, não como atores, mas como eles mesmos, falando sobre sua experiência, tal como no espetáculo Cour d'Honneur, do coreógrafo francês Jérôme Bel, que traz a cena depoimentos de espectadores que falam sobre sua própria experiência como espectadores na Cour d'Honneur durante o Festival de Avignon (França).

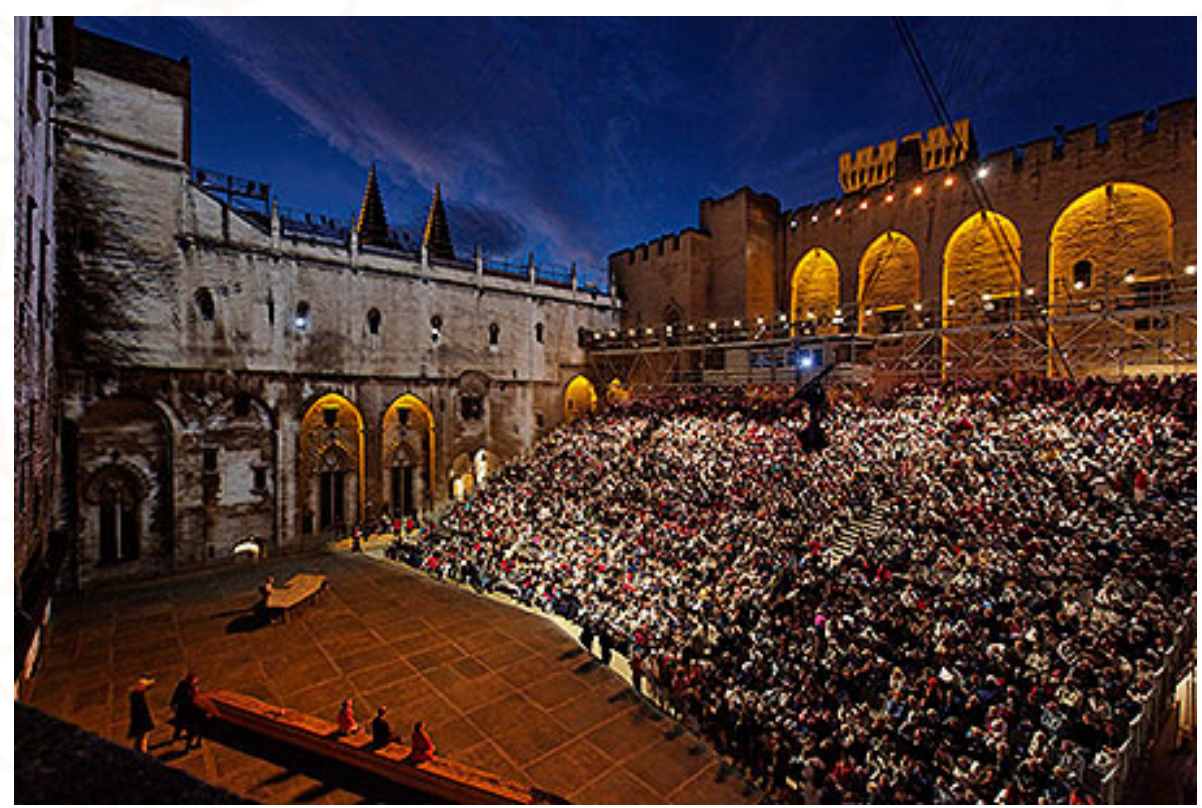

Figura 3 - Espetáculo Cour d'Honneur. Direção Jérôme Bel.

Foto: Christophe Raynaud.

Quando se analisa os procedimentos trazidos pelas teatralidades contemporâneas e exemplificados por encenações como Go Down, Moses, dirigida por Romeo Castellucci (Itália), Dire ce qu'on ne pense pas dans des langues qu'on ne parle pas, dirigida por Antônio Araújo (Brasil), e Cour d'Honneur, dirigida por Jérôme Bel (França), tem-se uma pequena mostra de como a expansão da noção de teatro também ampliou as possibilidades físicas de lugares do espectador. Entretanto, quando se fala sobre o lugar subjetivo do espectador é ne- 
cessário se atentar à experiência do espectador real de tais teatralidades. Para cumprir tal tarefa, me propus a realizar mais de 150 entrevistas abertas (CARNEIRO, 2016) com espectadores desses espetáculos, sobre as quais me debruço para analisar de modo sintético o lugar do espectador nessas teatralidades.

Sentado no teatro, o espectador de Go Down, Moses vê-se obrigado a completar as imagens apresentadas em uma sequência aparentemente não dramática. O som hipnotizante criado por Scott Gibbons toca todo o corpo do espectador gerando uma espécie de torpor. Quando se verifica, através do discurso, a experiência do espectador, percebe-se que a significação é gerada de maneira muito próxima à descrita por Mervant-Roux (2006) em um primeiro extrato, ou seja, o espectador cria uma espécie de história narrativa para a peça apresentada.

O que chama a atenção é que há um segundo extrato de significação que se desenvolve ao longo do tempo e por meio de analogias entre as cenas apresentadas e as experiências de vida do espectador. Não há, portanto, uma alteração propriamente dita no lugar do espectador, mas uma valorização desse extrato que funciona por meio dessa relação, também encontrada em peças dramáticas em menor proporção.

No segundo caso analisado, do espetáculo Dire ce qu'on ne pense pas dans des langues qu'on ne parle pas encenado por Antônio Araújo, há uma mudança radical no lugar físico do espectador que deambula atrás das cenas da peça, inicialmente na porta do edifício da bolsa de valores de Bruxelas (Bélgica) e, posteriormente, em seu interior. Porém, pude verificar nas entrevistas que a experiência do espectador, ainda que permeada de sensações advindas da caminhada e da proximidade física com a cena, estão ainda mais próximas da que pode ser verificada em uma peça dramática. Há um segundo extrato de experiência que aparece em menor proporção e que trata de um tipo de reflexão social, ou seja, o espectador relaciona cenas da peça a experiências do dia a dia em seu ambiente social.

Verifica-se que ainda que haja uma mudança radical no lugar físico do espectador, seu lugar subjetivo permanece inalterado. O espectador continua a vir de fora do teatro, e para fora do teatro ele retorna após o espetáculo.

$\mathrm{Na}$ terceira experiência aqui trazida, encontramos fortes traços da metateatralidade presente em diversas encenações contemporâneas. Em Cour 
d'Honneur, Jérôme Bel traz ao palco pessoas que falam de suas experiências como espectadores, que estão deslocados momentaneamente de seu lugar de espectador para o do ator. No entanto, o lugar dos espectadores está aqui representado não por aqueles que estão no palco, mas por aqueles que, da plateia, observam atentamente os discursos dos espectadores que narram suas experiências. Ao mesmo tempo, é importante notar, conforme registrei em entrevista com um dos espectadores-participantes do espetáculo, que, excluído o momento em que ele conta sua experiência, em todo o restante da encenação os espectadores, ainda que expostos, retomavam seu lugar de espectador.

Portanto, ao considerar-se que há dois conceitos de lugar, o físico e o subjetivo, percebe-se que as teatralidades contemporâneas têm radicalizado no que diz respeito ao lugar físico do espectador, mas que o lugar humano do espectador contemporâneo continua sendo o mesmo tanto diante de teatralidades mais tradicionais quanto diante das mais radicais.

Deve-se ter clareza de que por mais que a cena chamada contemporânea ou pós-dramática tenha trazido inovações formais e alterado a relação espacial do espectador com a encenação, ela não altera, em si, o lugar do espectador, pois este é imprescindível à existência do próprio teatro.

Nas pesquisas de campo efetuadas, fica evidente que seja qual for o tipo de espetáculo o espectador o fruirá a partir das experiências anteriores e de sua disposição atual em rearranjar os elementos da encenação. Assim sendo, qualquer tentativa generalizante de se cunhar uma teoria a partir do espectador corre o risco de falsear, pois vizinho ao espectador que é fã do teatro pós-dramático habita o que nunca foi ao teatro. Parece muito mais produtivo a proposição de teorias que se foquem sobre a realidade observada e narrada por espectadores, pois o espectador contemporâneo a despeito de uma ou outra teoria, de um ou outro tipo de teatro, se constrói na experiência individual e coletiva dentro de uma cultura a qual reserva para ele um lugar dentro do teatro.

\section{Referências bibliográficas}

ALMADA, I. Boal: embaixador do teatro brasileiro. Monografia não publicada apresentada como resultado do concurso PROAC n. 28. Pesquisa em Artes Cênicas, 2012. Disponível em: <https://institutoaugustoboal.files.wordpress.com/2012/11/ almada_monografia_boal.pdf>. Acesso em: 12 dez. 2015. 
ARANTES, Urias Corrêa. Artaud: teatro e cultura. Campinas: Editora Unicamp, 1988. ARISTÓTELES. Metafísica, Ética à Nicômaco, Poética. São Paulo: Abril Cultural, 1984.

ARTAUD, Antonin. Oeuvres complètes, v. IV. Paris: Gallimard, 1984.

O teatro e seu duplo. São Paulo: Martins Fontes, 1993.

BABLET, Denis. Le lieu, la scénographie et le spectateur. Théâtre/Public (Le rôle du spectateur), n. 55, Gennevilliers, janvier-février, 1984.

BARBA, Eugenio. O espaço interno. Sala Preta, Brasil, v. 8, p. 9-10, nov. 2008. Disponível em: <http://www.revistas.usp.br/salapreta/article/view/57345/60327>. Acesso em: 16 dez. 2015.

BARTHES, Roland. Oeuvres completes. Paris: Seuil, 2002.

BLAU, Herbert. The audience. Baltimore: Johns Hopkins University Press, 1990.

BOAL, Augusto. A estética do oprimido: reflexões errantes sobre o pensamento do ponto de vista estético e não científico. Rio de Janeiro: Funarte/Garamond, 2009. . Técnicas latino-americanas de teatro popular. São Paulo: Hucitec, 1988. Teatro do Oprimido. Rio de Janeiro: Civilização Brasileira, 1980.

BOUKO, Catherine. Théâtre et Réception: le spectateur postdramatique. Bruxelas: Peter Lang, 2010.

BRECHT, Bertolt. Teatro dialético. Rio de Janeiro: Civilização Brasileira, 1967.

BROOK, Peter. O teatro e seu espaço. Petrópolis: Vozes, 1970.

CABANNE, Pierre. Conversaciones con Marcel Duchamp. Barcelona: Anagrama, 1967.

CARNEIRO, Leonel Martins. A experiência do espectador contemporâneo: memória, invenção e narrativa. Tese (doutorado em teoria e prática do teatro) - Escola de Comunicações e Artes, Universidade de São Paulo, São Paulo, 2016.

A atenção nas teorias do teatro do século XX: de Stanislávski à Lehmann. Saarbrücken: Novas Edições Acadêmicas, 2015.

DELDIME, Roger; PIGEON, Jeanne. La mémoire du Jeune Spectateur. Bruxelas: De Boeck, 1988.

DESGRANGES, Flávio. A inversão da olhadela: alterações no ato do espectador teatral. São Paulo: Hucitec, 2012.

DEWEY, John. Arte como experiência. São Paulo: Martins Fontes, 2010.

The later works, 1925-1953, vol. 10, 1934: Art as Experience. Carbondale: Southern Illinois University Press, 2008a.

The later works, 1925-1953, vol. 1, 1925: Experience and Nature. Carbondale: Southern Illinois University Press, 2008b.

DOAT, Jan. Entrée du public: la psychologie collective et le théâtre. Paris: Éditions de Flore, 1947.

DORT, Bernard. O teatro e sua realidade. São Paulo: Perspectiva, 1977.

Théâtre public (1953-1966). Paris: Seuil, 1967. 
Théâtres: essais. Paris: Seuil, 1986.

La représentation émancipée. Arles: Actes Sud, 1988.

DUVIGNAUD, Jean. Sociologie du théâtre: essai sur les ombres collectives. Paris:

Presses Universitaires de France, 1965.

EVRÉINOFF, Nicolas. Le théâtre dans la vie. Paris: Librarie Stock, 1930.

FÉRAL, Josette. O real na arte: a estética do choque In: RAMOS, L. F. (Org.). Arte e ciência: abismo de rosas. Porto Alegre: Abrace, 2012.

Por uma poética da performatividade: o teatro performativo. Sala Preta, São Paulo, v. 8, p. 197-210, 2008.

FERNANDES, Sílvia Telesi. Teatralidades contemporâneas. São Paulo: Perspectiva, 2010.

; GUINBUSRG, J. (Org.). O pós-dramático: um conceito operativo?. São Paulo: Perspectiva, 2009.

FISCHER-LICHTE, Erika. The transformative power of performance. Londres: Routledge, 2008.

FREIRE, Paulo. Pedagogia do oprimido. Rio de Janeiro: Paz e Terra, 1994.

FRESHWATER, Helen. Theatre $\&$ audience. Nova York: Palgrave Macmillan, 2009.

GOETSCHEL, Pascale; YON, Jean-Claude (Org.). Au théâtre!: la sortie au spectacle, XIXe-XXle siècles. Paris: Publications de la Sorbonne, 2014.

GOFFMAN, Erving. Os quadros da experiência social. Petrópolis: Vozes, 2011.

GONON, Anne. In vivo: les figures du spectateur des arts de la rue. Montpellier:

L'Entretemps, 2011.

GORDON, Eric. The urban spectator: American concept cities from Kodak to Goo-

gle. Hanover: Dartmouth College Press /University Press of New England, 2010.

GOURDON, Anne-Marie. Théâtre, public, perception. Paris: CNRS, 1982.

GROTOWSKI, Jerzy. Em busca de um teatro pobre. Rio de Janeiro: Civilização Brasileira, 1971.

HALBWACHS, M. A memória coletiva. Tradução Beatriz Sidou. São Paulo: Centauro, 2006

HOLZER, W. O lugar na Geografia Humanista. Revista Território, Rio de Janeiro, ano IV, n. 7, p. 67-78, 1999. Disponível em: <http://www.revistaterritorio.com.br/ pdf/07_6_holzer.pdf>. Acesso em: 3 mar. 2017.

HUNKELER, Thomas, et al. Place au public: les spectateur du théâtre contemporain. Genève: Metis Presses, 2008.

JAUSS, Hans Robert. Pour une esthétique de la réception. Paris: Gallimard, 1978. KAPROW, Allan. Assemblage, environments and happenings. New York: Abrams, 1966.

KNOWLES, Ric. How theatre means. Nova York: Palgrave Macmillan, 2014.

KONIGSON, Elie. Diviser pour jouer. Les Cahiers de la Comédie-Française, edição especial Le Spectateur, v. 11, p. 42-49, 1994. 
LOUVAT-MOLOZAY, Bénédicte; SALAÜN, F. Le spectateur de théâtre à l'âge classique: XVIle et XVIIle siècles. Montpellier: l'Entretemps, 2008.

MACHON, Josephine. Immersive theatres: intimacy and immediacy in contemporary performance. Nova York: Palgrave Macmillan, 2013.

MERVANT-ROUX, Marie-Madeleine. Le créateur obscur. Les Cahiers de la Comédie-Française, edição especial Le Spectateur, v. 11, p. 55-69, 1994.

L'assise du théâtre: pour une étude du spectateur. Paris: CRNS, 1998.

Figurations du spectateur: une réflexion par l'image sur le théâtre et sur sa théorie. Paris: Harmattan, 2006.

Os dois teatros. Sala Preta, São Paulo, v. 12, n. 1, p. 125-140, jun. 2012.

Disponível em: <http://www.revistas.usp.br/salapreta/article/view/57552/60597>. Acesso em: 13 jan. 2013.

O grande ressonador: o que a antropologia histórica e uma abordagem etnográfica da sala de teatro podem nos dizer sobre o público. Revista aSPAs, v. 3, n. 1, p. 3-22, 2013. Disponível em: <http://revistas.usp.br/aspas/article/view/68382>. Acesso em: 12 abr. 2014.

MEYERHOLD, Vsevolod. Do teatro. São Paulo: lluminuras, 2012.

MÜNSTERBERG, Hugo. The film: a psychological study. New York: Dover Publications, 2004.

NAUGRETTE, Florence. Le plaisir du spectateur de théâtre. Rosny-sous-Bois: Bréal, 2002.

NEVEUX, Olivier. Politiques du spectateur: les enjeux du théâtre politique aujourd'hui. Paris: La Découverte, 2013.

PAVIS, Patrice. L'Analyse des spectacles. Paris: Armand Colin, 2012.

PISCATOR, Erwin. Teatro político. Rio de Janeiro: Civilização Brasileira, 1968.

RUBY, Christian. La figure du spectateur: éléments d'histoire culturelle européenne. Paris: A. Colin, 2012.

SAUER, Carl Ortwin. The morphology of landscape. In: LEIGHLY, J. (Org.). Land and life: a selection from the writings of Carl Ortwin Sauer. Berkeley: University of California Press, 1969. p. 315-350.

SPOLIN, Viola. Improvisação para o teatro. São Paulo: Perspectiva, 2010.

STANISLAVSKY, Constantin. A preparação do ator. Rio de Janeiro: Civilização Brasileira, 1984.

El trabajo del actor sobre si mismo: en el proceso creador de la vivencia. Tradução e notas Jorge Saura (a partir da versão russa). Barcelona: Alba Editorial, 2010. STERNE, Jonathan. The audible past: cultural origins of sound reproduction. Durham/London: Duke University Press, 2003.

UBERSFELD, Anne. Lire le théâtre 2: L'École du spectateur. Paris: Belin, 1996.

VICTOROFF, David. Le paradoxe du spectateur. Théâtre populaire, n. 12, p. 77-82, mar.-abr., 1955. 
L'applaudissement, une conduite sociale. Paris: Presses Universitaires de France, 1957.

VIGOTSKI, Lev Semionovitch. A formação social da mente. São Paulo: Martins Fontes, 1991.

WEHLE, Philippa. Le théâtre populaire selon Jean Vilar. Avignon: Actes Sud, 1981. WHITE, Gareth. Audience participation in theatre: aesthetics of the invitation. New York: Palgrave Macmillan, 2013.

Recebido em 03/04/2017

Aprovado em 26/04/2017

Publicado em 17/07/2017 